\title{
A Retrospective Analysis of Death Among Chinese Han Patients with Schizophrenia from Shandong
}

\author{
Li-li Hu', Qing Wang', ${ }^{2,3}$ Yan-hu Wang', Ling-xi Gu', Tian-gui Yu' \\ 'Department of Public Health, Shandong Mental Health Center, Jinan, People's Republic of China; ${ }^{2}$ Department of Biostatistics, School of Public \\ Health, Cheeloo College of Medicine, Shandong University, Jinan, People's Republic of China; ${ }^{3}$ Institute for Medical Dataology, Shandong University, \\ Jinan, People's Republic of China
}

Correspondence: Tian-gui Yu, Department of Public Health, Shandong Mental Health Center, Jinan, People’s Republic of China, Tel +86-53I-86336798, Email sdyutg@I63.com

Purpose: To describe the mortality rate and cause of death among Han Chinese schizophrenia patients and to explore the risk factors affecting survival.

Methods: We performed a retrospective analysis of death among patients with schizophrenia from Jan 1, 2012, to Dec 31, 2019, using the Severe Mental Disorders Information System of Shandong Province (henceforth referred to as the SMDI system) in Shandong, China. The cohort included 72,102 patients, and 11,766 patients died during follow-up. The data in this cohort study were derived from the SMDI system. We calculated the crude mortality rate and standardized mortality rate (SMR, standardized according to the sex and age composition of the population in Shandong Province) for patients with schizophrenia. Cox regression analysis was used to analyze the risk factors affecting patient survival, and the statistical index was the hazard ratio (HR).

Results: The mean age of the cohort patients was $47.21 \pm 14.05$ years; $51.79 \%$ were males, and $48.21 \%$ were females. Among them, $68.98 \%(49,735)$ had only a primary education level, $85.36 \%(61,549)$ were farmers, $64.37 \%(46,413)$ were married, and $94.01 \%$ $(67,775)$ received community management. A total of $16.32 \%$ of the cohort died. The SMR in patients with schizophrenia was 4.9 , and it was higher for males than females (4.99 versus 4.82). Among the 6 registered causes of death, physical illness had the highest SMR (5.15), followed by other causes of death (4.86), mental illness-related complications (4.57), homicide (4.31), accidents (4.13), and suicide (3.87). Higher levels of education, employment (in-service status), marriage, and urban residence were protective factors for survival among patients with schizophrenia.

Conclusion: In China, the SMR of schizophrenia is relatively high, and physical diseases are the main cause of death. We suggest that a variety of measures should be taken early to treat somatic diseases and reduce SMR in patients with schizophrenia.

Keywords: schizophrenia, cause of death, mortality, physical illness

\section{Introduction}

Schizophrenia is often described as one of the most severe mental disorders that affects approximately $1 \%$ of people. ${ }^{1}$ One major reason is that patients with schizophrenia have higher mortality rates than the general population, corresponding to a significant reduction in average life expectancy. ${ }^{2-4}$ Moreover, the gap between the mortality of patients with schizophrenia and the general population has widened in recent decades. ${ }^{5-8 .}$ Clearly, an improved evidence base is important for identifying at-risk groups, developing interventions, and addressing premature mortality.

In recent years, a series of studies have been carried out on premature mortality among patients with schizophrenia. Nevertheless, the causes have not been fully understood until now. Although unnatural causes such as suicide, ${ }^{7,8}$ and accidents ${ }^{9}$ account for a nontrivial part of the premature mortality, the vast majority of the premature mortality of patients with schizophrenia result from natural causes mainly composed of physical diseases such as cardiovascular diseases respiratory problems, diabetes and cancer. ${ }^{2,3,10-14}$ Underlying mechanisms that might explain the premature mortality of natural causes in patients with schizophrenia compared with the general population include unhealthy lifestyles, such as smoking, drinking, substance abuse and physical inactivity. ${ }^{15}$ In addition to schizophrenia per se, some antipsychotics 
increase the adverse effects of serious diseases such as metabolic syndrome, diabetes, and atherosclerosis, some of which are even life-threatening. ${ }^{16}$

To our knowledge, most studies on premature mortality in schizophrenia have primarily been conducted in Western countries. China's domestic research on the mortality rate and causes of schizophrenia is insufficient. Most of the domestic studies were on schizophrenia patients in western China. ${ }^{17}$ Considering that China, especially mainland China, differs largely from Western countries in terms of background ethnicity, health care systems, availability of clinical and community services, and relevant health indexes such as obesity and smoking rates. ${ }^{18}$ Western mortality estimates for schizophrenia may not be generalizable to China.

In China, the National Continuing Management and Intervention Program for Psychoses (also known as the "686 Program"), which includes schizophrenia and five additional severe mental disorders, was implemented in 2004. Later, the "686 Program" evolved into the national essential public health service, ${ }^{19}$ which made it possible to provide free regular follow-up and rehabilitation guidance to these patients in their communities. Additionally, the establishment of a severe mental health disorder system (henceforth referred to as the SMHD system) provided an opportunity to revisit the improvements in schizophrenia mortality. By the end of 2019, Shandong province had managed nearly 440,000 patients with severe mental disorders, $66 \%$ of whom were schizophrenics. The Han nationality accounted for more than $99.7 \%$ of this population. The ratio of male to female was $97.62: 100$. The age distribution was mainly $18-59$ years old. $81 \%$ of patients lived in rural areas. Doctors or nurses at community health centers follow up patients regularly to record their symptoms, social functioning, sleep and medication status.

The latest epidemiological studies reported that the overall lifetime prevalence of schizophrenia was 5.44 per 1000 up to July $2013 .{ }^{20}$ A 10 -year prospective cohort reported that the standardized mortality ratio (SMR) for the whole cohort was 4.0; for men, it was 4.9, and for women, it was 3.3, with all 64 deaths in the schizophrenia group occurring from natural causes. ${ }^{21}$ Among these 64 deaths, the specific causes of death in 42 cases were known, including various cancers, heart disease, respiratory disease, and other diseases. A 10-year follow-up investigation among a 1994 cohort of patients with schizophrenia showed that SMR for both suicide and deaths due to other causes (accident and natural causes) was highest in young patients and lowest in geriatric patients. ${ }^{22}$ A population-based nested case-control study indicated considerably decreased mortality from natural death in patients with schizophrenia using antipsychotics. ${ }^{23}$

To protect patients' health, China enacted a mental health law in 2013, and Shandong Province enacted mental health regulations in 2019. The Shandong provincial government released a document in 2018 to ensure free treatment for people with severe mental disorders. We conducted a retrospective study on Han Chinese patients with schizophrenia identified from the SMHDS of Shandong Province, China, to thoroughly clarify the characterizations of mortality in schizophrenia patients in the Chinese mainland after the implementation of the "686 Program", especially to answer the following questions: 1 . What are the main factors currently leading to mortality in Han Chinese patients with schizophrenia? 2. What are the effects of the policies introduced in recent years on the mortality rate of schizophrenia patients? By characterizing key sources of premature mortality in a large cohort with schizophrenia, the results provide a more comprehensive picture of the gap in mortality, thus highlighting the need for more effective strategies to improve the medical care of this patient population.

\section{Materials and Methods Study Population}

The study population was identified based on the SMHD system, which includes the following conditions. (1) They had been registered in primary medical and health institutions before December 31, 2011. (2) They had lived in the location for more than half a year. (3) They were Han patients with schizophrenia in Shandong Province. These patients were first screened by the trained staff of primary medical and health institutions according to the "Identification List of Mental Behavior Abnormalities" (11 items) and then confirmed by senior psychiatrists designated by the local health department according to the ICD-10.

Normally, these patients come from two populations: they were either from primary medical and health institutions or they were treated at home after outpatient treatment in mental hospitals or hospitalization. With the patient's consent, 


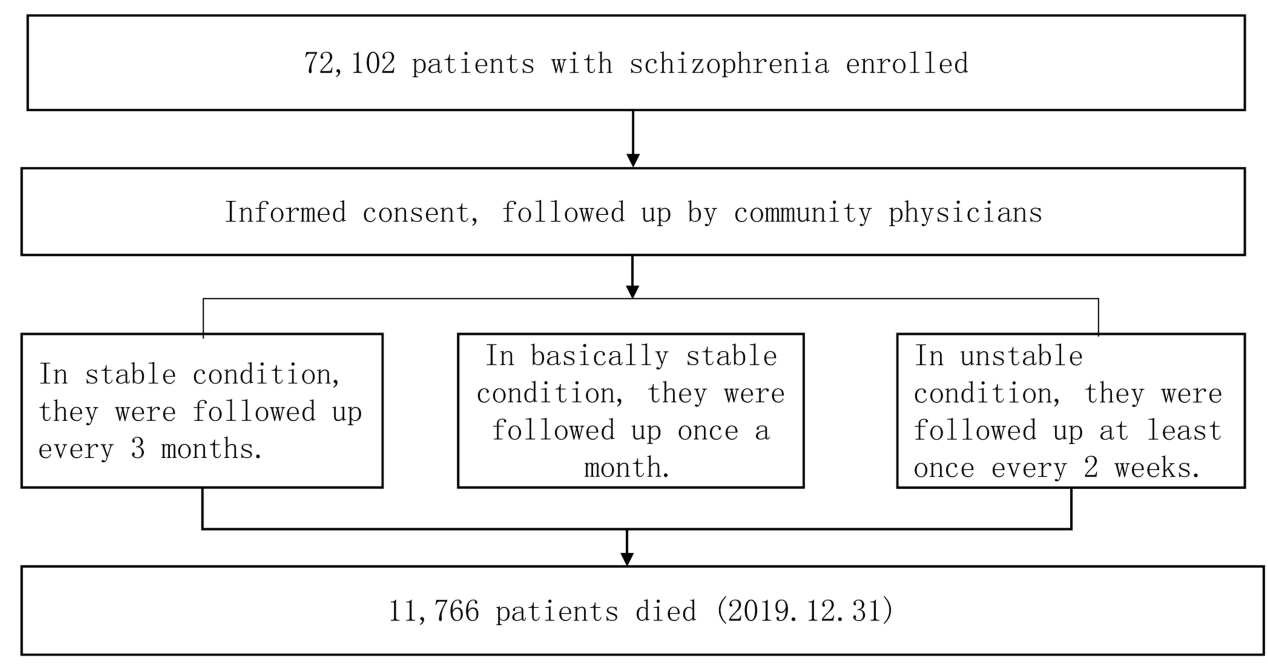

Figure I Community management process for patients with schizophrenia.

they will receive regular follow-up services from primary medical and health institutions. The SMHD system records the patient's information as follows: (1) general demographic information (location, sex, age, race, marriage, education levels, income, and profession), (2) medical history (family history of mental illness, current diagnosis, date of initial diagnosis of schizophrenia, and the use of antipsychotic medicines), (3) information related to death (time of death, cause of death, and manner of death).

Ethical review batch number (Reference No. ECSHCMSMHC2019R42) was approved by the institutional research ethics committee of Shandong Mental Health Center. Before participating in community service management, patients or their family members were needed to sign a paper informed consent form.

There were 72,102 patients with schizophrenics in Shandong province at the end of 2011. Between 2012 and 2019, they received follow-up management services from community health services. The staff managed the patients according to their condition during each visit. A total of 11,766 patients died during that period show in Figure 1.

\section{Selection of Study Subjects}

We identified all patients from the study population who died between Jan 1, 2012, and Dec 31, 2019. The causes and manner of death were identified by the SMHD system administrator according to death certificates written generally by ordinary physicians or by forensic specialists if death was sudden or crime was suspected. The default causes and manner of death in the SMHD system were divided into six categories as follows: physical illness, comorbidities related to mental illness, suicide, homicide, accident, and others.

\section{Statistical Analysis}

We analyzed the crude mortality ratios (CMRs) and standardized mortality ratios (SMRs) in individuals with schizophrenia and compared them with the general population (Website of Shandong Bureau of Statistics). The death and population data were sorted out and standardized by age and sex. According to the death information of schizophrenia patients, the death composition of different feature stratifications was calculated. Cox survival analysis was adopted to analyze the characteristics of the cohort and establish a survival model to explore the factors affecting the survival of patients with schizophrenia. All statistical analyses were conducted using SPSS 22.0 software. 
Table I Baseline Characteristics

\begin{tabular}{|c|c|c|c|c|c|}
\hline \multicolumn{2}{|l|}{ Characteristics } & \multicolumn{2}{|c|}{ Male } & \multicolumn{2}{|c|}{ Female } \\
\hline & & $\mathbf{N}$ & $\%$ & $\mathbf{N}$ & $\%$ \\
\hline \multirow[t]{3}{*}{ Age Group } & $10-39$ years & $|I, 88|$ & 34.18 & 9240 & 24.74 \\
\hline & $40-59$ years & 10,715 & 30.83 & 11,270 & 30.18 \\
\hline & $60-$ years & 12,162 & 34.99 & 16,834 & 45.08 \\
\hline \multirow[t]{3}{*}{ Education Level } & Primary schools and below & 21,968 & 63.20 & 27,767 & 74.35 \\
\hline & Junior/senior high school & 10,205 & 29.36 & 7912 & 21.19 \\
\hline & Junior college and above & 2585 & 7.44 & 1665 & 4.46 \\
\hline \multirow[t]{2}{*}{ Urban and rural areas } & Urban & 3771 & 10.85 & 3336 & 8.93 \\
\hline & Rural & 30,987 & 89.15 & 34,008 & 91.07 \\
\hline \multirow[t]{2}{*}{ Family history } & No & 27,663 & 79.59 & 31,103 & 83.29 \\
\hline & Yes & 7095 & 20.41 & 6241 & 16.71 \\
\hline \multirow[t]{3}{*}{ Professional } & Farmers & 29,129 & 83.81 & 32,420 & 86.81 \\
\hline & Workers and technicians & 2208 & 6.35 & 2152 & 5.76 \\
\hline & Laid off/unemployed/retired & 3421 & 9.84 & 2772 & 7.42 \\
\hline \multirow[t]{3}{*}{ Marriage status } & Unmarried & 15,740 & 45.28 & 3310 & 8.86 \\
\hline & Married & 15,706 & 45.19 & 30,707 & 82.23 \\
\hline & Divorced/widowed & 3312 & 9.53 & 3327 & 8.91 \\
\hline \multirow[t]{4}{*}{ Follow-up time } & $0-2$ years & 33,762 & 97.13 & 36,228 & 97.01 \\
\hline & $2-4$ years & 32,337 & 93.03 & 35,269 & 94.44 \\
\hline & 4-6 years & 30,421 & 87.52 & 33,643 & 90.09 \\
\hline & $6-8$ years & 28,643 & $82.4 I$ & 31,880 & 85.37 \\
\hline
\end{tabular}

Notes: The data of the study cohort were obtained from the Mental Disorders Information System of Shandong Province.

\section{Results}

\section{Demographic Characteristics}

The basic characteristics of the study population are shown in Table 1. A total of 72,102 patients with schizophrenia, including 34,758 males and 37,344 females, were included in the Severe Mental Disorders Management Program at the end of 2011 and were followed up from January 2012 to December 2019. The average age for males was 45.33 years (range 10-101) and 48.95 years for females (range 10-104). Elderly individuals (60- years old), primary school or below, rural residents, no family history, farmers, and married people were the majority. In male patients, the proportion gap between married and unmarried is small; among the female patients, the majority were married (83.23\%), while the proportion of unmarried patients was relatively low. The mean follow-up time was 7.56 years (range: $0.1-8$ years), and 11,766 patients died.

\section{All Causes Mortality}

Differences in SMR for different characteristics of schizophrenia are shown in Table 2.The SMR was the highest in patients aged 10-39 years (5.49), followed by those aged over 60 years. The SMR of patients with primary school education or below (5.14) was higher than that of patients with other education. The SMR of rural patients (4.91) was 
Table 2 Different Characteristics of Death in Schizophrenia Patients, SMRs and 95\% Cls

\begin{tabular}{|c|c|c|c|c|c|c|c|c|c|c|}
\hline \multicolumn{2}{|l|}{ Characteristics } & \multicolumn{3}{|c|}{ Total } & \multicolumn{3}{|c|}{ Male } & \multicolumn{3}{|c|}{ Female } \\
\hline & & $\mathbf{N}$ & CMR & $\operatorname{SMR}(95 \% \mathrm{Cl})$ & $\mathbf{N}$ & CMR & $\operatorname{SMR}(95 \% \mathrm{Cl})$ & $\mathbf{N}$ & CMR & $\operatorname{SMR}(95 \% \mathrm{Cl})$ \\
\hline \multirow[t]{3}{*}{ Age Groups } & $10-39$ years & 1502 & 275.19 & $5.49(5.34-5.63)$ & 961 & 368.64 & $5.52(5.38-5.66)$ & 541 & 189.87 & $5.46(5.32-5.60)$ \\
\hline & $40-59$ years & 2434 & 892.43 & $4.01(3.88-4.13)$ & 1458 & 1091.36 & $3.99(3.87-4.11)$ & 976 & 711.04 & $4.03(3.91-4.15)$ \\
\hline & $60-$ years & 7830 & 988.07 & $4.85(4.72-4.99)$ & 3784 & 919.50 & $4.50(4.37-4.63)$ & 4046 & 1051.47 & $5.16(5.02-5.29)$ \\
\hline \multirow[t]{3}{*}{ Education Level } & Primary schools and below & 9571 & 1753.53 & $5.14(5.0 \mathrm{I}-5.28)$ & 4744 & 1819.82 & $5.09(5.0 \mathrm{I}-5.19)$ & 4827 & 1990.61 & $5.17(5.04-5.31)$ \\
\hline & Junior/senior high school & 1829 & 335.10 & $4.06(3.93-4.18)$ & 1208 & 463.39 & $4.11(3.93-4.19)$ & 621 & 256.09 & $4.02(3.90-4.14)$ \\
\hline & Junior college and above & 366 & 67.06 & $4.10(3.98-4.22)$ & 251 & 96.28 & $4.14(4.14-4.26)$ & 115 & 47.42 & $4.10(3.98-4.23)$ \\
\hline \multirow[t]{2}{*}{ Urban and rural areas } & Urban & 705 & 129.17 & $4.74(4.6 I-4.87)$ & 423 & 162.26 & $4.68(4.6 I-4.74)$ & 282 & 116.29 & $4.87(4.74-5.01)$ \\
\hline & Rural & $|I, 06|$ & 2026.52 & $4.91(4.78-5.05)$ & 5780 & 2217.24 & $4.83(4.78-4.90)$ & 5281 & 2177.83 & $4.99(4.86-5.13)$ \\
\hline \multirow[t]{2}{*}{ Family history } & No & 11,275 & 2085.00 & $4.90(4.76-5.03)$ & 5847 & 2281.30 & $4.81(4.68-4.95)$ & 5328 & 1869.90 & $4.99(4.85-5.12)$ \\
\hline & Yes & 491 & 90.80 & $4.96(4.83-5.10)$ & 256 & 98.20 & $4.94(4.8 I-5.08)$ & 235 & 82.48 & $4.98(4.85-5.12)$ \\
\hline \multirow[t]{3}{*}{ Professional } & Farmers & 10,265 & 1898.24 & $4.92(4.78-5.05)$ & 5346 & 2050.75 & $4.83(4.70-4.97)$ & 4919 & 1726.36 & $5.00(4.87-5.14)$ \\
\hline & Workers and technicians & 475 & 87.84 & $4.73(4.59-4.86)$ & 259 & 99.35 & $4.68(4.55-4.8 I)$ & 216 & 75.80 & $4.78(4.65-4.92)$ \\
\hline & Laid off/unemployed/retired & 1026 & 189.73 & $4.81(4.68-4.95)$ & 598 & 229.40 & $4.76(4.63-4.89)$ & 428 & $\mid 50.21$ & $4.92(4.79-5.06)$ \\
\hline \multirow[t]{3}{*}{ Marriage status } & Unmarried & 2734 & 500.90 & $4.13(4.01-4.26)$ & 2374 & 910.68 & $4.25(4.12-4.38)$ & 360 & 148.46 & $3.88(3.76-4.00)$ \\
\hline & Married & 7329 & 1342.77 & $5.16(5.02-5.30)$ & 3018 & 1157.72 & $5.34(5.20-5.17)$ & 4311 & |777.8| & $4.99(4.85-5.12)$ \\
\hline & Divorced/widowed & 1703 & 312.01 & $5.33(5.19-5.47)$ & 811 & 311.10 & $4.98(4.85-5.11)$ & 892 & 313.05 & $5.64(5.50-5.78)$ \\
\hline
\end{tabular}

Notes: The death data of schizophrenia patients were obtained from the Mental Disorders Information System of Shandong Province. The general population data was obtained from the IIth National Population Census of Shandong Province (Shandong Statistical Bulletin).

Abbreviation: SMR, standardized mortality ratio (standardized for age and sex). 


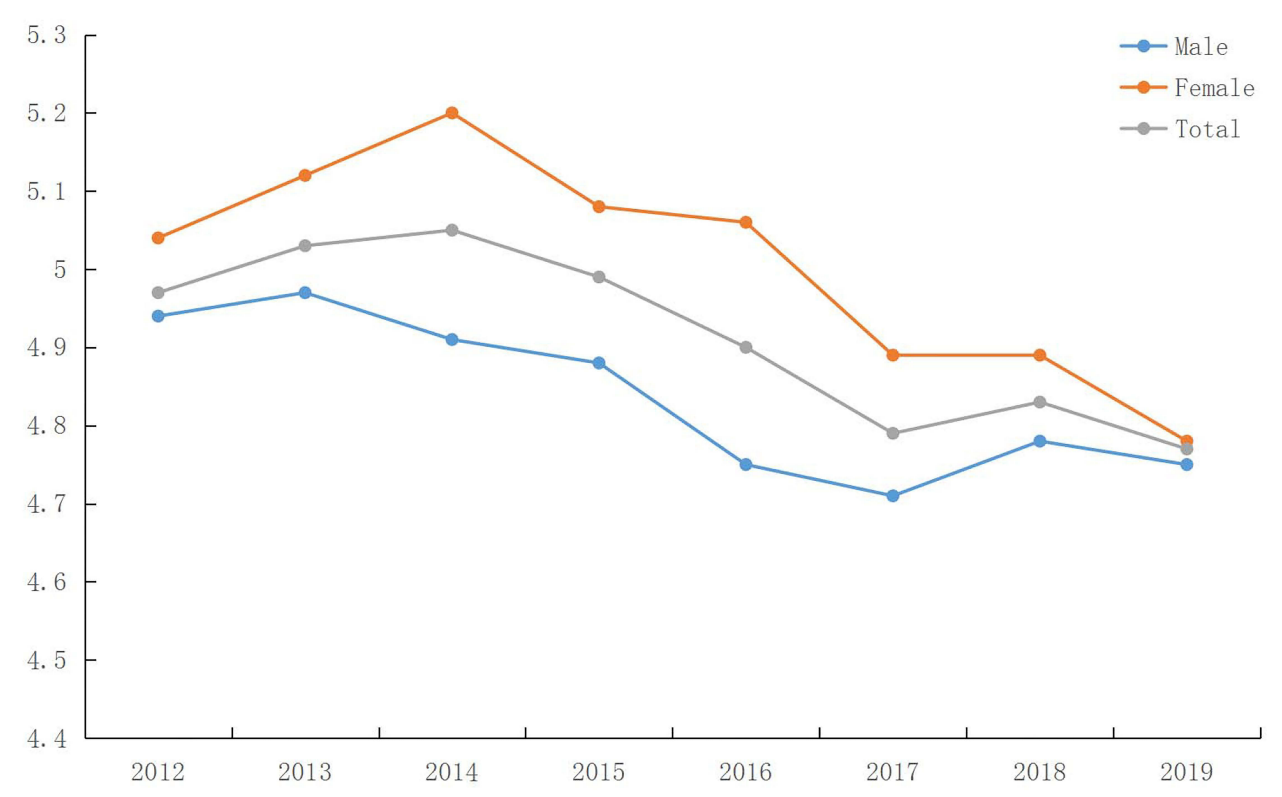

Figure 2 Trends in SMR-follow-up time in patients with schizophrenia (Jan I, 20I2-Dec 3I, 2019). The death data of schizophrenia patients were obtained from the Mental Disorders Information System of Shandong Province. The general population data was obtained from the I Ith National Population Census of Shandong Province (Shandong Statistical Bulletin).

Abbreviation: SMR, standardized mortality ratio (standardized for age and gender).

higher than that of urban patients (4.74). 491 patients had a family history of mental illness, with a slightly higher SMR than patients without a family history. SMR varied according to the patient's occupation. The SMR of farmers was higher than that of other occupational patients. Divorced and widowed patients had the highest SMR (5.33), while unmarried patients had the lowest (5.16). From 2011 to 2013, the SMR of patients with schizophrenia showed an increasing trend, and gradually decreased after 2014 show in Figure 2.

\section{Natural Causes of Death}

Differences in SMR for different causes of schizophrenia are shown in Table 3. The CMR for schizophrenia was 2155.51 per 100,000 years, and the SMR was 4.90. Male's CMR was higher than that of females, but the opposite was true for the SMR.In schizophrenia, $66.88 \%$ of patients died of natural causes, and $11.40 \%$ died of unnatural causes. The CMR from natural causes was 1441.70 per 100,000 years, and the SMR was 5.10 (95\% CI, 4.97-5.24), with the SMR of female patients slightly higher than that of male patients (5.14 vs 5.06). For patients who died of natural causes, $92.46 \%$ died from physical illness, and the SMR was 5.15 (95\% CI, 5.02-5.20); 7.54\% of patients died from mental illnessrelated complications, and the SMR was 4.57 (95\% CI, 4.44-4.71).

\section{Unnatural Causes of Death}

Patients with schizophrenia who died of unnatural causes had a CMR of 245.69 per 100,000 years and a SMR of 4.02 (95\% CI, 3.90-4.15), which was higher in female than in male (4.13 vs 3.96) show in Table 3. Accident accounted for approximately $60 \%$ of unnatural deaths, and the SMR was 4.13 (4.01-4.17). Suicide accounts for nearly $38.85 \%$ of unnatural deaths, and female have a higher SMR than male (3.97 vs 3.77). In this cohort, a total of 13 patients with schizophrenia died from homicide (6 males and 7 females), and the SMR of male was higher than that of female.

\section{Factors Influencing Patient Survival}

We incorporated all patient data into the Cox regression analysis model and used the first group of each variable as the reference group show in Table 4. For patients with schizophrenia, workers and technicians, high education and being married are protective factors for survival $(\mathrm{HR}=0.678,0.664,0.791)$. Divorced/widowed and living in rural areas are risk factors $(\mathrm{HR}=1.270,1.778)$. 
Table 3 Causes of Death in Schizophrenia Patients, SMRs and $95 \% \mathrm{Cl}$

\begin{tabular}{|l|c|c|c|c|c|c|c|c|c|}
\hline \multirow{2}{*}{ Causes of Death } & \multicolumn{3}{|c|}{ Total } & \multicolumn{3}{c|}{ Male } & \multicolumn{3}{c|}{ Female } \\
\cline { 2 - 11 } & N & CMR & SMR (95\% CI) & N & CMR & SMR (95\% Cl) & N & CMR & SMR (95\% CI) \\
\hline All causes & 11,766 & 2155.51 & $4.90(4.77-5.03)$ & 6203 & 2379.12 & $4.82(4.69-4.95)$ & 5563 & 1952.37 & $4.99(4.85-5.12)$ \\
\hline Natural causes & 7869 & 1441.70 & $5.10(4.97-5.24)$ & 4076 & 1563.57 & $5.06(4.92-5.19)$ & 3793 & 1331.38 & $5.14(5.01-5.28)$ \\
\hline Mental illness related complications & 593 & 108.65 & $4.57(4.44-4.71)$ & 320 & 122.75 & $4.40(4.28-4.44)$ & 273 & 95.81 & $4.86(4.73-4.90)$ \\
\hline Physical illness & 7276 & 1333.06 & $5.15(5.02-5.20)$ & 3756 & 1440.82 & $5.13(5.00-5.18)$ & 3520 & 1235.37 & $5.17(5.03-5.21)$ \\
\hline Unnatural causes & 1341 & 245.69 & $4.02(3.90-4.15)$ & 769 & 294.99 & $3.96(3.83-4.08)$ & 572 & 200.75 & $4.13(4.00-4.25)$ \\
\hline Accident & 807 & 147.85 & $4.13(4.01-4.17)$ & 487 & 186.82 & $4.06(3.93-4.09)$ & 320 & 112.31 & $4.27(4.14-4.31)$ \\
\hline Homicide & 13 & 2.38 & $4.31(4.19-4.35)$ & 6 & 2.30 & $5.44(5.30-5.48)$ & 7 & 2.46 & $3.65(3.54-3.69)$ \\
\hline Suicide & 521 & 95.45 & $3.87(3.75-3.90)$ & 276 & 105.87 & $3.77(3.65-3.81)$ & 245 & 85.98 & $3.97(3.85-4.01)$ \\
\hline Other causes & 2556 & 468.11 & $4.86(4.73-4.99)$ & 1358 & 520.55 & $4.73(4.60-4.77)$ & 1198 & 420.43 & $5.01(4.87-5.05)$ \\
\hline
\end{tabular}

Notes: CMR are expressed per 100000 person-years. Male and female SMRs are standardized for age.

Abbreviation: SMR, standardized mortality ratio (standardized for age and sex). 
Table 4 Adjusted HRs for All-Cause Mortality in Patients with Schizophrenia

\begin{tabular}{|c|c|c|c|c|c|c|c|c|}
\hline \multicolumn{2}{|l|}{ Characteristics } & \multirow[t]{2}{*}{ Reference } & \multicolumn{2}{|c|}{ All Causes } & \multicolumn{2}{|c|}{ Natural Causes } & \multicolumn{2}{|c|}{ Unnatural Causes } \\
\hline & & & HR (95\% Cl) & $\mathbf{P}$ & HR (95\% Cl) & $\mathbf{P}$ & HR (95\% Cl) & $P$ value \\
\hline \multirow[t]{2}{*}{ Professional } & Workers and technicians & \multirow[t]{2}{*}{ Farmers } & $0.678(0.6 \mid 8-0.743)$ & 0.000 & $0.691(0.618-0.773)$ & 0.000 & $0.491(0.365-0.662)$ & 0.000 \\
\hline & Laid off/unemployed & & $0.998(0.936-1.065)$ & 0.963 & $3.966(3.892-31.046)$ & 0.396 & $0.704(0.567-0.875)$ & 0.002 \\
\hline \multirow[t]{2}{*}{ Education Level } & Junior/senior high school & \multirow[t]{2}{*}{ Primary schools and below } & $0.664(0.631-0.699)$ & 0.000 & $0.647(0.607-0.690)$ & 0.000 & $1.500(1.162-1.937)$ & 0.002 \\
\hline & Junior college and above & & $0.566(0.509-0.628)$ & 0.000 & $0.532(0.465-0.609)$ & 0.000 & $1.180(0.902-1.545)$ & 0.227 \\
\hline \multirow[t]{2}{*}{ Marriage status } & Married & \multirow[t]{2}{*}{ Unmarried } & $0.791(0.753-0.831)$ & 0.000 & $0.78 \mathrm{I}(0.734-0.83 \mathrm{I})$ & 0.000 & $0.960(0.836-1.103)$ & 0.564 \\
\hline & Divorced/widowed & & $1.270(1.191-1.353)$ & 0.000 & 1.275 (I.I79-I.379) & 0.000 & $1.150(0.938-1.409)$ & 0.180 \\
\hline Urban and rural areas & Rural & Urban & $1.778(1.647-1.918)$ & 0.000 & $1.760(1.604-1.930)$ & 0.000 & $3.250(2.436-4.336)$ & 0.000 \\
\hline
\end{tabular}

Notes: Models derived from Cox regression analyses. Adjusted for age and sex. Family history was not included because of coefficient no convergence.

Abbreviation: HR, hazard ratio. 


\section{Discussion}

\section{SMR in Patients with Schizophrenia}

Over the past decade, several studies have shown that people with schizophrenia have higher mortality rates than the general population. ${ }^{24}$ Our research also proves this point. The SMR among Han patients with schizophrenia was 4.9 in eastern China. It is not only higher than the general population but also higher than other regions in our study. Some previous studies reported significantly higher all-cause mortality in patients with schizophrenia (2.4) among South Korean participants. ${ }^{5}$ A study in Finland showed that all-cause SMR remained stable from 1984 (2.6) to 2014 (2.7). ${ }^{25}$ A national retrospective longitudinal cohort of adults with schizophrenia in the United States showed that the all-cause SMR was 3.7. ${ }^{14}$

Our study showed that male patients had a higher CMR than female patients, and after the age structure was standardized, SMR was the opposite. The reason for this difference may be that the proportion of male elderly patients in the total population is higher than that of female patients. Some studies have shown the opposite, with men having a higher SMR than women. ${ }^{26}$

Divorced/widowed patients had a higher SMR than unmarried and married patients, which was also a risk factor for patient survival. The loss of life partners and lack of emotional support in daily life are not conducive to the recovery of the disease. A study in China showed that being married also endowed persons with schizophrenia with more familial support than their counterparts who were not married. ${ }^{27}$ Married persons with schizophrenia lived in families with higher economic status, were more likely to have a caregiver, were surrounded by more family members and were less likely to be maltreated by other family members. Female patients, in particular, have a low family economic status, and after divorce/widowhood, they generally lose their financial resources and are not guaranteed medical treatment.

In our study, $90 \%$ of patients with schizophrenia lived in rural areas, with an SMR higher than those living in urban areas. The difference in the distribution of mental health resources between urban and rural areas is due to the difference in the distribution of mental health resources. Most mental health institutions are concentrated in cities, and rural patients have poor access to medical and health services. Furthermore, the economic income of urban and rural patients is also a major influencing factor. A study in northern Europe showed that patterns of contact were different in rural, town and city surroundings, and with the exception of psychotherapy, the rural pattern was characterized by the use of less specialized services. ${ }^{28}$

Schizophrenia is a complex polygenic disease. The SMR is higher in patients with a family history of mental illness, suggesting that genetic factors may play a role in the outcome of schizophrenia deaths. A 14-year follow-up study in rural China showed that compared with individuals with a negative family history of schizophrenia, those with a positive family history of schizophrenia had a significantly higher rate of death. ${ }^{29}$ A case-control study by Laursen also found that a family history of mental disorders was associated with higher mortality from schizophrenia. ${ }^{30}$ A Danish populationbased study showed that schizophrenia was associated with the polygenic risk score, family psychiatric history, and socioeconomic status. ${ }^{31}$ Our study demonstrated that a family history of schizophrenia/psychoses is partly mediated through the individual's genetic liability.

From 2021 to 2019, SMR in patients with schizophrenia showed a trend of first increasing and then decreasing. This has something to do with the government attaching importance to mental health work and issuing a series of policies during this period. In 2013, the Mental Health Law of the People's Republic of China was promulgated to protect the legitimate rights and interests of people with mental disorders and regulate mental health services. In 2018, the Shandong Provincial People's government issued a document requiring free treatment for all patients with severe mental disorders, including schizophrenia. The economic burden and disease burden of patients are reduced, and treatment is guaranteed. In 2019, Shandong Province issued the Mental Health Regulations of Shandong Province in light of local conditions, clarifying the responsibilities of all departments in the service management of severe mental disorders, and making project management more standardized and normalized.

\section{Causes of Death}

Multiple studies have shown that natural death is the leading cause of death in people with schizophrenia. In a US national cohort of adults with schizophrenia, excess deaths were from cardiovascular and respiratory diseases. ${ }^{14}$ The 
majority of deaths $(52.2 \%)$ were caused by natural diseases such as cardiovascular diseases and cancer (Finland). ${ }^{5}$ Natural (somatic) causes of death were the main cause of excess deaths, with more than half of the excess deaths in females (Sweden). ${ }^{32}$ In our study, natural causes were also the main cause of death in patients with schizophrenia, causing $66.88 \%$ of deaths, and the SMR was 5.10. Physical diseases account for more than $90 \%$ of natural causes of death. Some physical diseases are more common in people with schizophrenia, such as cardiovascular disease, cerebrovascular disease hyperlipidemia, and diabetes. Studies have shown that people with schizophrenia have fewer primary care contacts than controls who receive poorer treatment of their medical diseases. ${ }^{33}$ Additionally, some chronic physical diseases are associated with unhealthy lifestyles (such as smoking, alcohol abuse, or high-fat and high-sugar diets). ${ }^{34}$

This suggests that physical diseases that account for a greater proportion of natural deaths should be preventable by taking a series of measures. Patients can reduce the occurrence of chronic diseases by adopting a healthy lifestyle, such as quitting smoking and drinking alcohol, eating a low-salt diet, avoiding high-calorie foods, and increasing physical exercise. Additionally, going to medical institutions to receive regular physical examinations can also be early detection of physical diseases and early intervention.

The main causes of unnatural death are accidents and suicide. In Denmark, a survey based on the national registry shows that Schizophrenia is a strong independent risk factor for accidental Deaths. ${ }^{9}$ A National Cohort study of all Swedish adult has revealed accidental death are more common than suicides. ${ }^{35}$ In addition to the influencing factors indicated by previous studies, drinking is a more significant characteristic of Shandong province population. Drinking alcohol has an effect on accidents. Our previous study also showed that the prevalence of alcohol use disorder among residents over 18 years old in Shandong province was $5.27 \% .^{36}$

We can promote health education in the future to strengthen the responsibility of relevant departments and guardians' consciousness as week as their safety consciousness to mobilize them to provide more attention. Additionally, strengthening the control of drugs and toxic substances and establishing a sound, long-term social and family support system are important measures for reducing the accidental death of patients with schizophrenia.

\section{Limitations}

There was bias in the selection of research objects. Schizophrenia patients with documented management in 2011 were not included in our study if their diagnoses changed over the next few years (no schizophrenia). The causes of death of patients with schizophrenia are determined out by doctors in primary health care institutions, and there may have been inaccurate categorizations. In this study, the description of the complications of physical and mental diseases was relatively macroscopic, and the names of diseases were not specified.

\section{Conclusions}

The SMR of Han Chinese schizophrenia patients is higher than that of the general population and higher than that of some countries. Natural death stations account for more than $60 \%$ of deaths from schizophrenia. These causes of death can be prevented and controlled through early intervention.

\section{Ethics Approval}

The study was approved by the institutional research ethics committee of Shandong Mental Health Center (Reference No. ECSHCMSMHC2019R42) and the research adhered to tenets of the Declaration of Helsinki.

\section{Funding}

This study was supported by Traditional Chinese Medicine Science and Technology Project of Shandong Provincial Health Commission (No.2020M052).

\section{Disclosure}

The authors report no conflicts of interest in this work. 


\section{References}

1. Freedman R, Wood AJJ. Schizophrenia. N Engl J Med. 2003;349(18):1738-1749. doi:10.1056/NEJMra035458

2. Jayatilleke N, Hayes RD, Dutta R, et al. Contributions of specific causes of death to lost life expectancy in severe mental illness. Eur Psychiatry. 2017;43:109-115. doi:10.1016/j.eurpsy.2017.02.487

3. Laursen TM, Nordentoft M, Mortensen PB. Excess early mortality in schizophrenia. Annu Rev Clin Psychol. 2014;10:425-448. doi:10.1146/ annurev-clinpsy-032813-153657

4. Piotrowski P, Gondek TM, Królicka-Deręgowska A, Misiak B, Adamowski T, Kiejna A. Cause of mortality in schizophrenia: an updated review of European. Psychiatr Danub. 2017;29(2):108-120. doi:10.24869/psyd.2017.108

5. Tanskanen A, Tiihonen J, Taipale H. Mortality in schizophrenia: 30-year nationwide follow-up study. Acta Psychiatr Scand. 2018;138:492-499. doi:10.1111/acps.12913

6. Rosenbaum L. Closing the mortality gap-mental illness and medical care. $N$ Engl J Med. 2016;375(16):1585-1589. doi:10.1056/NEJMms1610125

7. Gatov E, Rosella L, Chiu M, Kurdyak PA. Trends in standardized mortality among individuals with schizophrenia, 1993-2012: a population-based, repeated cross-sectional study. CMAJ. 2017;189(37):E1177-E1187. doi:10.1503/cmaj.161351

8. Saha S, Chant D, Mcgrath J. A systematic review of mortality in schizophrenia: is the differential mortality gap worsening over time? Arch Gen Psychiatry. 2007;64(10):1123-1131. doi:10.1001/archpsyc.64.10.1123

9. Hellemose LAA, Laursen TM, Larsen JT, Toender A. Accidental deaths among persons with schizophrenia: a nationwide population-based cohort study. Schizophr Res. 2018;199:149-153. doi:10.1016/j.schres.2018.03.031

10. Ni L, Wu J, Long Y, et al. Mortality of site-specific cancer in patients with schizophrenia: a systematic review and meta-analysis. BMC Psychiatry. 2019;19(1):323. doi:10.1186/s12888-019-2332-z

11. Laursen TM. Causes of premature mortality in schizophrenia: a review of literature published in 2018. Curr Opin Psychiatry. 2019;32(5):388-393. doi:10.1097/YCO.0000000000000530

12. Walker ER, McGee RE, Druss BG. Mortality in mental disorders and global disease burden implications: a systematic review and meta-analysis. JAMA Psychiatry. 2015;72(4):334-341. doi:10.1001/jamapsychiatry.2014.2502

13. Correll CU, Solmi M, Veronese N, et al. Prevalence, incidence and mortality from cardiovascular disease in patients with pooled and specific severe mental illness: a large-scale meta-analysis of 3,211,768 patients and 113,383,368 controls. World Psychiatry. 2017b;16(2):163-180. doi:10.1002/ wps. 20420

14. Olfson M, Gerhard T, Huang C, Crystal S, Stroup TS. Premature mortality among adults with Schizophrenia in the United States. JAMA Psychiatry. 2015;72(12):1172-1181. doi:10.1001/jamapsychiatry.2015.1737

15. Auquier P, Lançon C, Rouillon F, Lader M, Holmes C. Mortality in schizophrenia. Pharmacoepidemiol Drug Saf. 2006;15(12):873-879. doi: $10.1002 /$ pds. 1325

16. Centorrino F, Goren JL, Hennen J, et al. Multiple versus single antipsychotic agents for hospitalized psychiatric patients: case-control study of risks versus benefits. Am J Psychiatry. 2004;161(4):700-706. doi:10.1176/appi.ajp.161.4.700

17. Ran MS, Chan CL, Chen EY, et al. Differences in mortality and suicidal behaviour between treated and never-treated people with schizophrenia in rural China. Br J Psychiatry. 2009;195(2):126-131. doi:10.1192/bjp.bp.108.055301

18. Zhang XY, Chen DC, Xiu MH, et al. Cigarette smoking and cognitive function in Chinese male schizophrenia: a case-control study. PLoS One. 2012;7(5):e36563. doi:10.1371/journal.pone.0036563

19. Song D, He J, Zhou W, Dai M, Zhou L. Primary development of community mental health service in Liuyang. Chin Mental Health J. 2011;25:517-520.

20. Long J, Huang G, Liang W, et al. The prevalence of schizophrenia in mainland China: evidence from epidemiological surveys. Acta Psychiatr Scand. 2014;130(4):244-256. doi:10.1111/acps.12296

21. Ran MS, Chen EY, Conwell Y, et al. Mortality in people with schizophrenia in rural China: 10-year cohort study. Br $J$ Psychiatry. 2007;190:237-242. doi:10.1192/bjp.bp.106.025155

22. Ran MS, Chan CL, Chen EY, et al. Mortality of geriatric and younger patients with schizophrenia in the community. Suicide Life Threat Behav. 2008;38(2):143-151. doi:10.1521/suli.2008.38.2.143

23. Chen Y, Yang X, Qin X, et al. Antipsychotics and risk of natural death in patients with schizophrenia. Neuropsychiatr Dis Treat. 2019;15:1863-1871. doi:10.2147/NDT.S199748

24. Kredentser MS, Martens PJ, Chochinov HM, Prior HJ. Cause and rate of death in people with schizophrenia across the lifespan: a population-based study in Manitoba, Canada. J Clin Psychiatry. 2014;75(2):154-161. doi:10.4088/JCP.13m08711

25. Ösby U, Westman J, Hällgren J, Gissler M. Mortality trends in cardiovascular causes in schizophrenia, bipolar and unipolar mood disorder in Sweden 1987-2010. Eur J Public Health. 2016;26(5):867-871. doi:10.1093/eurpub/ckv245

26. Brown S, Inskip H, Barraclough B. Causes of the excess mortality of schizophrenia. Br J Psychiatry. 2000;177:212-217. doi:10.1192/bjp.177.3.212

27. Ran MS, Wong YI, Yang SY, et al. Marriage and outcomes of people with schizophrenia in rural China: 14-year follow-up study. Schizophr Res. 2017;182:49-54. doi:10.1016/j.schres.2016.10

28. Sørgaard KW, Sandlund M, Heikkilä J, et al. Schizophrenia and contact with health and social services: a Nordic multi-centre study. Nord J Psychiatry. 2003;57(4):253-261. doi:10.1080/08039480310002138

29. Ran MS, Xiao Y, Zhao X, et al. Family history of psychosis and outcome of people with schizophrenia in rural China: 14-year follow-up study. Asian J Psychiatr. 2018;32:14-19. doi:10.1016/j.ajp.2017.11.016

30. Laursen TM, Trabjerg BB, Mors O, et al. Association of the polygenic risk score for schizophrenia with mortality and suicidal behavior - A Danish population-based study. Schizophr Res. 2017;184:122-127. doi:10.1016/j.schres.2016.12.001

31. Agerbo E, Sullivan PF, Vilhjálmsson BJ, et al. Polygenic Risk Score, parental socioeconomic status, family history of psychiatric disorders, and the risk for schizophrenia: a Danish Population-Based Study and meta-analysis. JAMA Psychiatry. 2015;72(7):635-641. doi:10.1001/ jamapsychiatry.2015.0346

32. Osby U, Correia N, Brandt L, Ekbom A, Sparén P. Mortality and causes of death in schizophrenia in Stockholm county, Sweden. Schizophr Res. 2000;45(1-2):21-28. doi:10.1016/s0920-9964(99)00191-7 
33. Copeland LA, Zeber JE, Wang CP, et al. Patterns of primary care and mortality among patients with schizophrenia or diabetes: a cluster analysis approach to the retrospective study of healthcare utilization. BMC Health Serv Res. 2009;9:127. doi:10.1186/1472-6963-9-127

34. Druss BG, Bradford WD, Rosenheck RA, Radford MJ, Krumholz HM. Quality of medical care and excess mortality in older patients with mental disorders. Arch Gen Psychiatry. 2001;58(6):565-572. doi:10.1001/archpsyc.58.6.565

35. Crump C, Sundquist K, Winkleby MA, Sundquist J. Mental disorders and risk of accidental death. Br J Psychiatry. 2013;203(3):297-302. doi:10.1192/bjp.bp.112.123992

36. Ruzhan W, Jingxuan Z, Yanhu W, et al. An epidemiological survey of mental disorders among people aged 18 and above in Shandong Province. Chin J Psychiatry. 2021;54(02):138-146. doi:10.3760/cma.j.cn113661-20200708-00323

\section{Publish your work in this journal}

Risk Management and Healthcare Policy is an international, peer-reviewed, open access journal focusing on all aspects of public health, policy, and preventative measures to promote good health and improve morbidity and mortality in the population. The journal welcomes submitted papers covering original research, basic science, clinical \& epidemiological studies, reviews and evaluations, guidelines, expert opinion and commentary, case reports and extended reports. The manuscript management system is completely online and includes a very quick and fair peer-review system, which is all easy to use. Visit http://www.dovepress.com/testimonials.php to read real quotes from published authors.

Submit your manuscript here: https://www.dovepress.com/risk-management-and-healthcare-policy-journal 